\title{
IMPACT OF APPLICATION SOFTWARE ON DIAGNOSIS OF SPEECH AND LANGUAGE DEVELOPMENT OF CHILDREN WITH HEARING IMPAIRMENT
}

\author{
Esad H. Mahmutović ${ }^{1}$ \\ Husnija Hasanbegović \\ Meliha Povlakić Hadžiefendić
}

Original scientific paper

University of Tuzla, Faculty of Education and Rehabilitation, Bosnia and Herzegovina

Center for Hearing and Speech Rehabilitation, Sarajevo, Bosnia and Herzegovina

Received: 12.12.2017

Accepted: 20.02.2018

\begin{abstract}
Aim of this paper was to examine effectiveness of speech and language development examination of persons with hearing impairment in form of applicable diagnostic software in relation to classical approach. Research was conducted on the sample of 45 respondents from the population of students with hearing impairments based on following criteria: degree of impairment above $80 \mathrm{~dB}$, age from 6 to 15 years without any other disabilities. Data was processed with descriptive analysis, Wilcoxon test and t-test. Results of the research confirmed that applicable diagnostic software provide more effective diagnostic procedures for examining of speach and language development of persons with hearing impairment in relation to classical approach.
\end{abstract}

Key words: speech and language development, effectiveness, diagnostic software

\section{INTRODUCTION}

Hearing loss is considered tobe the most prevalent congenital abnormality in newborns and is more than twice as prevalent as other conditions that are screened for at birth, such as sickle cell disease, hypothyroidism, phynilketonuria, and galactosaemia (Finitzo \& Crumley, 1999 according to Shemesh, 2013).
Depending on the degree of impairment, hearing impairment can cause milder or more severe deviations in the development of speech and language, to complete aphasia, in the case of deafness. Deviations are most prevalent in terms of articulation disorders, inadequate construct of meaning (understanding), adoption and use of words (naming concepts and situations), inadequacy of language statement - sentences, absence of grammatical rules and illiteracy.

\footnotetext{
${ }^{1}$ Correspondence to:

Esad H. Mahmutović, University of Tuzla, Faculty of Education and Rehabilitation, Bosnia and Herzegovina

Univerzitetska 1, 75000 Tuzla, Bosnia and Herzegovina

Phone: +38761290780

E-mail: esad25@yahoo.com
} 
There are no satisfactory results without timely detection and adequately conducted diagnostic procedures to evaluate all levels of developmental areas, especially the speech and language, and determine the initial platform for any action needed by the necessary methods and procedures based on scientific principles that respect the identified specifics of an individual.

According to Haug (2011) „A common goal of language testing in children is to see if a child's language development is following the expected course. To reach this goal, "a child's language skills are compared to the skills of same-age peers" (Johnston, 2007 , p. 1). Another goal of language testing might be to describe the child's current language abilities so that "language therapy and school programming can be individualized" (Johnston, 2007, pp. 1-2). A third reason for language testing would be the "measurement of progress, either for an individual child, or an educational or therapeutic program" (Johnston, 2007, p. 2)“.

Obviously, the issue of assessment is an important one. When it relates to children who are deaf and hard-of-hearing, the issue is at once both more complex and even more important. Perhaps the greatest challenge in assessing the skills of deaf learners whether in school testing, clinical assessment, or research - is ensuring that language is not a barrier. When potential communication problems are eliminated, most assessments (and assessors) assume that deaf and hearing children are much the same. It is often overlooked that the background, experiences, and knowledge of deaf students may not be the same as that of hearing students, regardless of the language or mode of communication they use. In order to fully understand the characteristics of deaf learners, including both strengths and weaknesses, it is necessary to understand the interactions of cognitive, social, and linguistic factors in the environment (Marschark, 2001). The problems of assessing deaf children's language development are due to the lack of assessment materials normed on deaf students and the inability of many examiners to fully communicate with and analyze the communication of deaf children (Easterbrooks \& Baker, 2002, according to Miller, 2006).

In order to evaluate the hearing impaired person well, it is also necessary to provide quality preparation for conducting diagnostic procedures, separating the optimal time and analyzing all aspects of functioning in different circumstances and contexts. The motivation of the respondent and the general functioning through diagnostic procedures that have subjective character- istics (concentration, attention, perception and memory) and cooperation are very important for optimum assessment.

If the assessment field is to move forward in meaningful ways, it is important to develop a general assessment framework that can be used with all deaf and hard of hearing children. This framework must have enough flexibility and rationality to fit the varying assessment and intervention needs of this heterogeneous population, including the necessary psychometric standards and guidelines for translating test data into meaningful intervention and/or programming strategies and approaches (Miller, 2006).

Scientific activity over the last thirty or many years is a condition of extremely noticeable and frequent technological and technical progress, which is constantly changing the necessary knowledge in all areas of human activity, resulting in rapid social development in those areas where this knowledge is practically applied.

When it comes to hearing impaired people, the application of technology is reflected in three basic areas of action: hearing impairment diagnosis, objective but also specific subjective diagnostic methods; amplification, through various types of hearing aids (individual and installable hearing aids, cochlear implants); education and re-habilitation through the application of different types of didactic tools and aids.

Computer technology for the deaf and hearing-impaired should mainly serve the improvement of communication and information processing tasks. Therefore the analogy for the deaf is - starting from the example of the blind: Take spoken language out from the acoustic channel and put it into the visual channel; that is: Write it. Computer aids cannot substitute everyday communication but they are inestimable tools for strengthening and broadening language competence and information processing. The point has to be stressed that communication skills are learnt by communicating with human beings. That means, we have to provide an education system in which the computer aids for deaf are embedded in a course system which secures the use of those aids (Dotter, 1996). According to Debevc i Peljhan (2004): „With the incredible speed of development of ICT and with the availability of high speed Internet, the study materials can be distributed in even more complex audio and video formats. Most frequently, it is presented as interactive video on demand (Deloddere, Verbiest \& Verhille, 1994). A video clip with sound is a very vital method of presenting information in a traditional written form. 
The mimicking and gesturing offered by a video clip tell us much more than just words and pictures in a book. However, the words, sounds and simple mimics and gestures are not always enough for successful teaching. of the deaf. In European projects like project SMILE (Sign language and Multimedia-based Interactive Language course for the deaf for learning European written languages)(Kronreif et al., 2000) and project VISIOCOM (Video-supported Online Communities)(Debevc, 2002) it has been determined that the deaf have poor reading and writing skills. That is to say that they frequently are not proficient in their own national or local language. Therefore, teachers must spend more time using different methods of teach-ing words and lack the time to teach the lesson material. Consequently, the deaf also have difficulties in understanding multimedia applications, which appear on the World Wide Web (WWW). The WWW has an overwhelming amount of information, which is available to everyone except the deaf who are not proficient in the written language and often do not know English. The situation is even more difficult because most of the educational institutions for the deaf in Europe do not have the best conditions for using ICT and because programs for teaching foreign languages like English at schools for the deaf are just being introduced.

There is no doubt that using computers in teaching deaf/hard of hearing students has come along way and proved its effectiveness. Computers and the many new and exciting software packages that have been developed in recent years are important tools that can help develop emerging literacy skills (Parette \& VanBiervliet, 1991, acorrding to Gaad i Qaryouti, 2002).

For deaf people it is extremely important to introduce the use of information and communications technology on all levels of education and rehabilitation. This increases their ability to learn and improves their understanding of learning materials, especially if the applications are designed specifically for their needs. Through daily exposure to a larger number of such materials, we can positively influence the literacy (reading and writing skills) of the deaf. With increased literacy, the deaf would be able to read literature, and subtitles, enabling them to receive information through written sources. Therefore, we can expect them to have a higher self-esteem, more easily integrate into society and have more opportunities for employment (Debevc \& Pljhan, 2004).

The justification for the use of software applications cannot be called into question when it comes to the deaf population of students because rehabilitation as well as most of the education is carried out individually through sessions, where the advantage in the specific capabilities of this media is unlimited, at least in problem training, which is characteristic of the processes of language learning. There are, of course, open questions as well as about the creation of computer software applications for which an audio-rehabilitator is required, as well as about the choice of educational content to be computerized (Hasanbegović, 2006).

Different ways - paths of conducting diagnostic procedures, from the aspect of organizing procedures and technical support, have a very important influence on setting up a clear and correct diagnosis. The efficiency and effectiveness of these methods depends on the time frame of their duration, the speed of processing and evaluation of the data collected, the accuracy and precision of the data collected, the speed and manner of data archiving, the availability of collected data, the speed and flow of collected information, the level of general functioning of the respondent when evaluated (attention, concentration, cooperation), possibilities of continuous evaluation and monitoring of the realization of the rehabilitation program.

The traditional (paper - pencil) way of evaluation, from an organization's point of view and technical support, implies that, when determining speech - language development, diagnostic procedures are carried out with the help of paper and as an incentive material (pictures, illustrations), but also as input forms, processing and evaluation of data. The data is entered manually, the numeric values are counted and processed subsequently and, differently selected, archived into personal files. This kind of evaluation in direct contact with the respondent, mainly due to poor interaction due to language non / competency, requires long lasting preparation of the child, diagnostician and material. Also, it takes too much time to conduct the examination, the fatigue of the respondent and examiners, leaves the possibility of overcoming some important elements for setting up an adequate diagnosis, hindering the repetition process and verifying the obtained results, and complicating access to the data collected. Developing software for deafness diagnosis, using model equations, numerical schemes, Dunmade, A. O., Dunmade, A. D., Taiwo, Tomori, and Komolafe, (2009), according to Mahmutović and Hasanbegović (2017) emphasize importance of computer technologies in the process of diagnosis, claiming that this software is an important tool for medical practitioner otorhinolaryngologists because it helps in determining severity of deafness in each individual patient case. 
They also point out that Dolinay, Zlinksy, and Vasek (2005) have developed a computer program that helps doctors and audiologists to calculate the percentage of hearing loss per Fowler-Sabine, calculating the average hearing loss and displaying audiometric curves, which can alongside others, be stored as a picture and can be archived for future queries.

The aim of the research conducted by Mahmutović and Hasanbegović (2017) was to examine effectiveness and efficiency of examination of hearing status of persons with hearing impairment in form of applicable diagnostic software, in relation to classical approach. Sample was comprised of 90 respondents and was formed out of two subsamples. First subsample was comprised of 45 students with hearing impairment with a degree of impairment of over $80 \mathrm{~dB}$, both genders, age from 6 to 15 years and without any other disabilities. Second subsample was comprised of 45 students (absolvents) from department of audiology. For data gathering, audiogram, applicable diagnostic software and scale for evaluation of attention and cooperation were used. Results of the research confirmed that applicable diagnostic software provide more effective and more efficient diagnostic procedures for examining hearing status of persons with hearing impairment in relation to classical approach. Significantly better effectiveness of conducting diagnostic procedures in favor of diagnostic software has been confirmed with evaluating percentage of hearing loss according to Fowler-Sabine and degree of hearing impairment, while presence of significantly better efficiency is confirmed on evaluated indicators: time, attention and cooperation of students during evaluation of hearing status.

Acorrding to Haug (2011): „The use of new technologies for the instruction and testing of both Deaf children and adults is very common today. Examples include web-based video lectures for Deaf students in Slovenia (Debevc \& Peljhan, 2004), a computer-based psychiatric diagnostic interview in ASL (Montoya et al., 2004), a computer-based test for Deaf children and young adolescents in DGS (Mann, 2008), a web-based version of the Test of American Sign Lan-guage (see Haug, 2008a), and the development of a computer-based environment in ASL for delivering performance-based content from kindergarten through high school (Hooper, Rose, \& Miller, 2005; Miller, Hooper, \& Rose, 2005). The increasing use of new technologies provides a good opportunity to exploit the use of video to meet the modality-specific features of sign languages in testing. The availability of new technologies has also contributed to the design of the test interface for the adapted DGS test.“
Macedo et al. (2004) presented a research with the help of created test battery (BALS On-line) to assess the development of language skills in Portuguese and Libras (Brazilian Sign Language) by deaf students via WWW. The battery consists of six tests, namely: Picture Naming by Matching Written Words (PNM On-line), Picture Naming by Spelling (PNS On-line), Sign Naming by Matching Written Words (SNM On-line), Sign Naming by Spelling (SNS On-line), Word Reading Competence (WRC On-line), Receptive Sign Vocabulary (RSV Online). The traditional paper-and-pencil versions have been standardized with a sample of 1158 deaf students. Aim of this paper was to examine effectiveness of speech and language development examination of persons with hearing impairment in form of applicable diagnostic software in relation to classical approach.

It was assumed that there is significant advantage in favor of applying diagnostic software in effectiveness of diagnostic procedures, considering the basic indicators of speech and language development.

\section{METHODS}

\section{Sample of respondents}

Research was conducted on the sample of 45 respondents from the population of students with hearing impairments based on following criteria: degree of impairment above $80 \mathrm{~dB}$, age from 6 to 15 years without any other disabilities.

\section{Measuring instruments and sample of variables}

Measuring instruments were tests and diagnostic patterns of speech-language development, prepared in two different forms (media), for implementation in two different ways.

The first, classical (paper - pencil) form, where the test material (incentive material - pictures, input forms for entering of evaluation results) is on paper and the other, computerized, where the complete, same test material is embedded in the form of computer-application - in this case, diagnostic software. For the evaluation of speechlanguage development, modified and mutually combined, Articulation Test, according to Vuletić (1990), from which the standards for assessment of voice articulation are taken and Test Lingvogram (Kostić, Vladisavljević, Blagojević, 1983) from which stimulation material (drawings) and word list formulas for estimating basic speech-language development indicators are taken, were used (Figure 1, Figure 2, Figure 3). 
A sample of the Articulation Test variables used in this research: total correctly pronounced voices - exact repeating of words, total articulation errors in repeating words, omission in pronunciation, substitution in pronunciation, distortion in exclamation.

A sample of Lingvogram variables used in this research: correct understanding of words, accurate naming of concepts, partial naming of concepts, reading of words with understanding, reading of words without understanding, writing words, total word errors, writing omission, writing substitution, writing addition, writing metathesis.

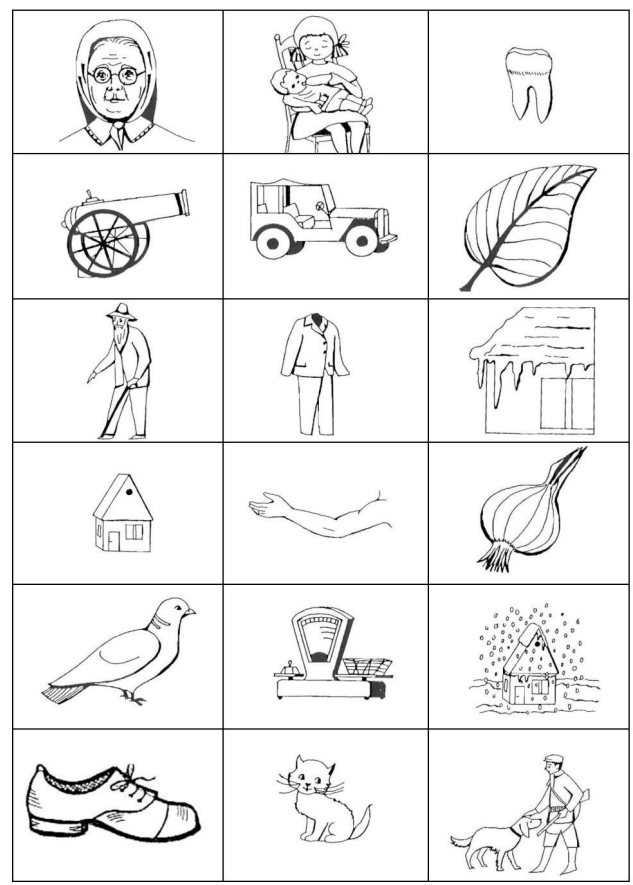

Figure 1 Classical diagnostics

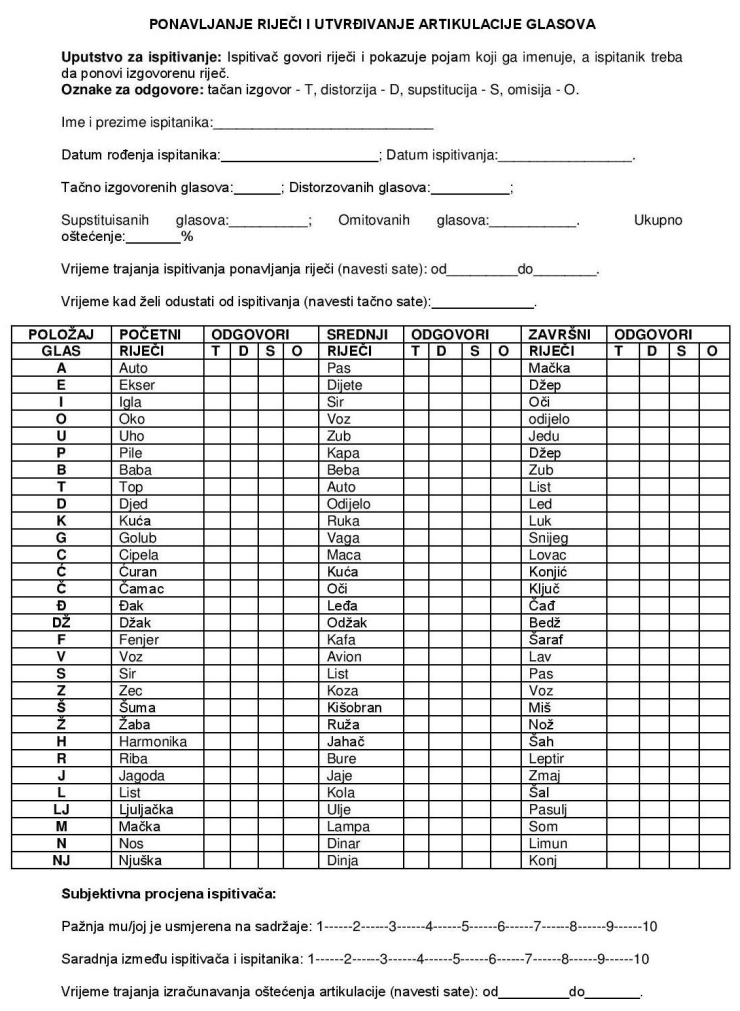

Figure 2 Classical diagnostics

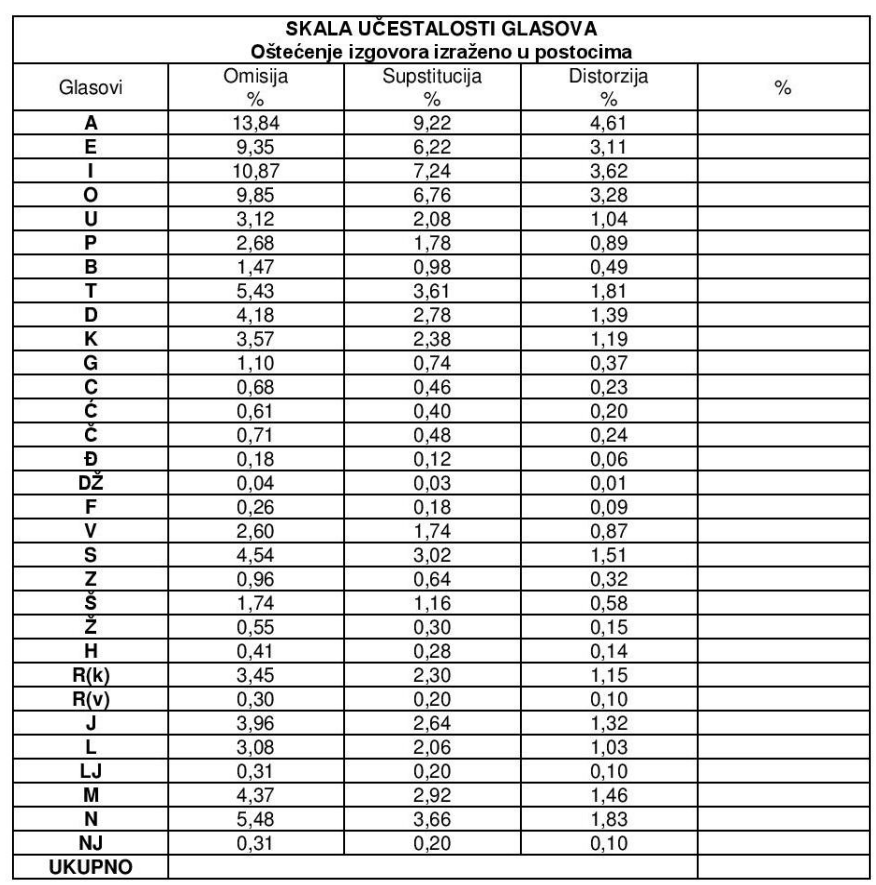

Figure 3 Classical diagnostics

Diagnostic software represented digital-diagnostic product but it can be also used in rehabilitation purposes in the process of rehabilitation of speech and listening. It was arranged in form of diagnostic procedures (measuring instruments) and database for storing, querying and printing stored evaluation results through findings, opinions or, if needed, in some other form. Program has four segments, which, combined together comprise unique diagnostic whole (Mahmutović \& Hasanbegović, 2017).

The third segment provides an evaluation of the basic indicators of speech-language development. It consists of a combination of two modified, mutually combined and computerized tests (Articulation Test and Lingvogram). It is possible to determine the described speech-language parameters (variables), so that all the stimulating image appears on the left side of the display, and on the right are the commands for responding of the respondents. The examiner, by pressing the appropriate button, selects the option to accumulate results in a common database, from where it can be retracted to print findings and opinions (Figure 4). 


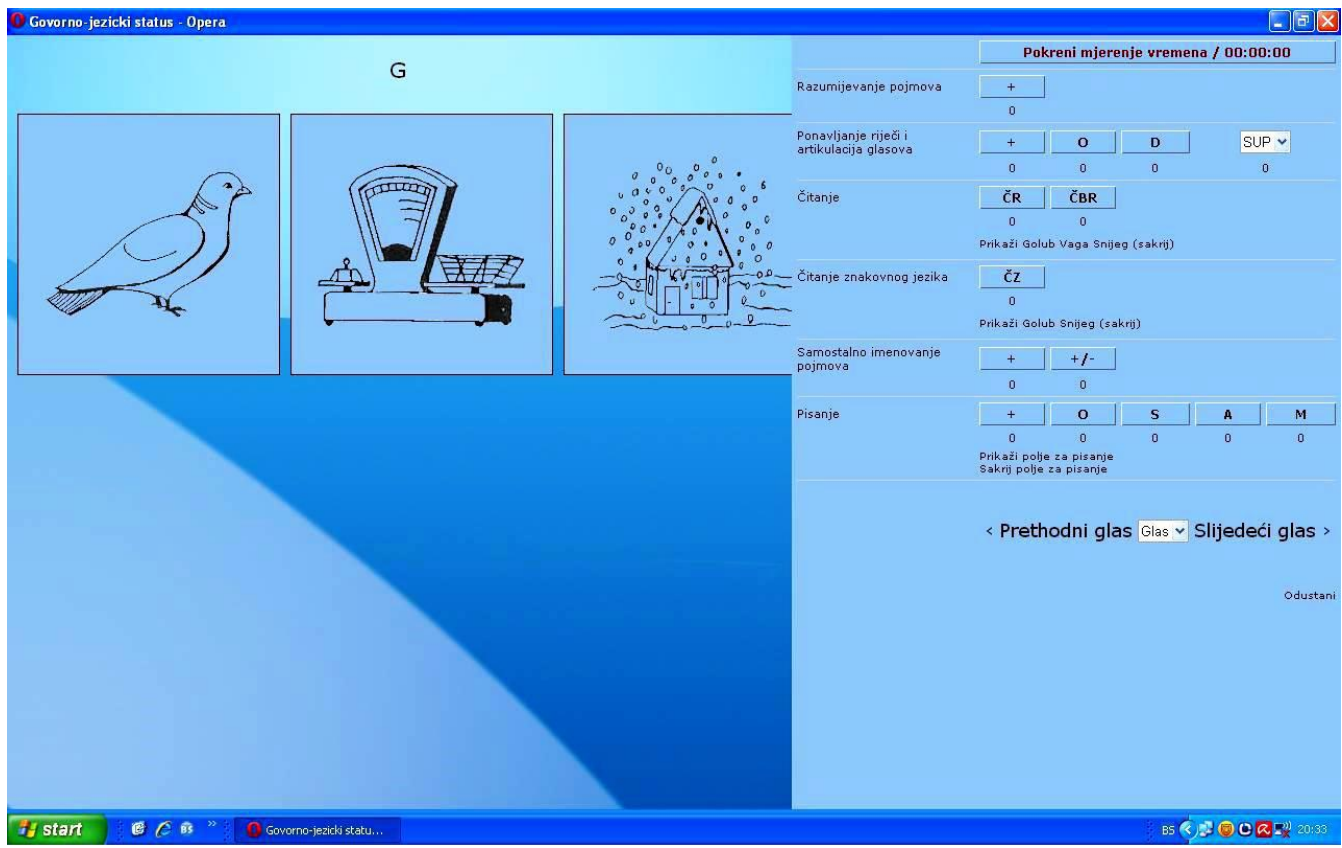

Figure 4 Diagnostic software

\section{Research conducting manner}

An experimental method was used in the research. The evaluation was done in teams and was conducted by three team members. The first part of the evaluation was carried out using the aforementioned diagnostic procedures - the tests in a classic way (paper - pencil) and the other through the same tests in the form (media) of the computerized diagnostic program. The classical examination was conducted so that one member of the team was questioning the pupil, the others recorded the results of the variables for the evaluation of effectiveness, and all three jointly verified the accuracy of the results. When examining with the application software, the test was performed by the same examiner, and the results were automatically recorded in the software.

\section{Data processing methods}

SPSS for Windows was used to process data. In order to make decision on conducting adequate tests and analysis, Shapiro-Wilk test $(\mathrm{N}<50)$ was used for evaluation of normal distribution. Data was processed by descriptive analysis.

To test the differences in determining the effectiveness of diagnostic procedures for the evaluation of speech-language development, obtained from two different ways (media), thirteen variables belonging to nonparametric statistics were used, the Wilcoxon rank test was used, and for the three variables belong- ing to the parametric statistic t-test for repeated measurements was used.

\section{RESULTS AND DISCUSSION}

Although most language teachers today stress the development of oral skills in their teaching, it is very difficult for them to find time to assess these skills. The general consensus in foreign- and second-language education is that oral skill development is a high priority, indeed in many cases, the top priority. If, in fact, speaking is emphasized, it should also be tested periodically. However, assessing oral skills requires a significant commitment of time and energy on the part of language teachers. In an effort to mitigate this testing burden, testing software has been developed that allows teachers to construct computerized oral tests, to administer them, and to massess students' responses with relative ease. Using this kind of software in conjunction with an appropriate scoring technique, teachers can assess their students' oral performance on a relatively frequent basis with a minimal loss of classroom time (Larson, 2000). Evaluating all segments of speech-language development of children with hearing impairment should represent a steady process. The reason for this is the use of a treatment that continually seeks to cause change, which is why it is important to constantly check it, monitor it - evaluate it. Continuous monitoring gives insight into development levels, but rates the treatment too, which should be continued, modified or completely changed. 
Procedures in the diagnostic process, in addition, should not become self-purposive. They also need to be verified, with regard to the applied content, the timeliness, the means of evaluation, the effectiveness and the efficiency of implementation in all individual development areas.

Table 1 shows basic statistical parameters of the results on the applied variables. The most significant mean-value deviations of respondents in both modes of evaluation are expressed in the following variables: correctly understands words, correctly names concepts, reads words with understanding, reads words without understanding and literally writes words.

By comparing the range of responses and the arithmetic means of the largest difference, between the two modes of evaluation, they are also observed on variables: correctly understands words, correctly names concepts, reads words with understanding, reads words without understanding and literally writes words, but also on the variables total errors in writing, writing omission, and writing addition.

Table 1 Basic statistical parameters

\begin{tabular}{|c|c|c|c|c|c|}
\hline Variables & Evaluation type & Min & Max & $\mathbf{M}$ & Sd \\
\hline \multirow[t]{2}{*}{ RAZURIJE } & Classical & 13 & 90 & 63.76 & 21.65 \\
\hline & Software & 22 & 90 & 70.40 & 15.86 \\
\hline \multirow[t]{2}{*}{ IMENPOJM } & Classical & 13 & 88 & 58.71 & 21.54 \\
\hline & Software & 12 & 89 & 60.36 & 21.26 \\
\hline \multirow[t]{2}{*}{ DJIMPOJM } & Classical & 0 & 37 & 11.18 & 9.58 \\
\hline & Software & 0 & 37 & 10.96 & 9.53 \\
\hline \multirow[t]{2}{*}{ PONARIJE } & Classical & 8 & 30 & 19.20 & 5.33 \\
\hline & Software & 8 & 30 & 19.58 & 5,06 \\
\hline \multirow[t]{2}{*}{ UKGRPORI } & Classical & 0 & 24 & 11.07 & 5.61 \\
\hline & Software & 0 & 28 & 10.76 & 5.94 \\
\hline \multirow[t]{2}{*}{ OMISIZGO } & Classical & 0 & 8 & .62 & 1.76 \\
\hline & Software & 0 & 8 & .78 & 1.81 \\
\hline \multirow[t]{2}{*}{ SUPSIZGO } & Classical & 0 & 13 & 3.29 & 3.01 \\
\hline & Software & 0 & 13 & 3.38 & 3.37 \\
\hline \multirow[t]{2}{*}{ DISTIZGO } & Classical & 0 & 18 & 7.16 & 4.25 \\
\hline & Software & 0 & 17 & 6.60 & 4.02 \\
\hline \multirow[t]{2}{*}{ ČITARIRA } & Classical & 22 & 90 & 71.53 & 16.49 \\
\hline & Software & 21 & 90 & 75.31 & 14.86 \\
\hline \multirow[t]{2}{*}{ ČITARIBR } & Classical & 0 & 68 & 17.96 & 16.81 \\
\hline & Software & 0 & 69 & 14.67 & 14.88 \\
\hline \multirow[t]{2}{*}{ PISERIJE } & Classical & 7 & 90 & 52.98 & 21.37 \\
\hline & Software & 11 & 87 & 57.02 & 21.86 \\
\hline \multirow[t]{2}{*}{ UKGRPIRI } & Classical & 0 & 28 & 9.38 & 6.28 \\
\hline & Software & 0 & 30 & 10.91 & 6.32 \\
\hline \multirow[t]{2}{*}{ OMISPISA } & Classical & 0 & 5 & 1.11 & 1.34 \\
\hline & Software & 0 & 11 & 1.78 & 2.20 \\
\hline \multirow[t]{2}{*}{ SUPSPISA } & Classical & 0 & 21 & 6.07 & 4.36 \\
\hline & Software & 0 & 15 & 5.53 & 3.65 \\
\hline \multirow[t]{2}{*}{ ADICIJA } & Classical & 0 & 7 & 1.38 & 1.56 \\
\hline & Software & 0 & 15 & 2.56 & 2.78 \\
\hline \multirow[t]{2}{*}{ METATEZA } & Classical & 0 & 5 & .82 & 1.25 \\
\hline & Software & 0 & 9 & 1.18 & 1.91 \\
\hline
\end{tabular}

\section{LEGEND:}

RAZURIJE - Understanding words IMENPOJM - Naming of concepts DJIMPOJM - Partial naming of concepts PONARIJE - Word repeating

UKGRPORI - Total errors in repeating the word

OMISIZGO - Pronunciation omission

SUPSIZGO - Pronunciation substitution

DISTIZGO - Pronunciation distortion
ČITARIRA - Reading words with understanding ČITARIBR - Reading words without understanding PISERIJE - Word writing UKGRPIRI - Total errors in writing OMISPISA - Writing omission SUPSPISA - Writing substitution ADICIJA - Writing addition METATEZA - Writing metathesis 
Through the Wilcoxon test, it was found that differences, in nine out of thirteen variables, that were determined by descriptive analysis, in addition to diagnostic significance are statistically significant too (Table 2). There is a statistically significant increase in the benefit of diagnostic software on variables that define the basic indicators of speech-language development: the number of words students understand $(\mathrm{Z}=-3.28, \mathrm{p}=.00)$, concepts that they correctly name $(Z=-2.05, p=.04)$, words that they read with understanding $(Z=-3.65, p=.00)$, words that they read without understanding $(\mathrm{z}=-3.03, \mathrm{p}=.00)$ and words that they correctly write $(Z=-2.71, p=.01)$. However, it is important to emphasize that students make and statistically significantly exceed the total number of errors in writing $(\mathrm{z}=-4.86, \mathrm{p}=.00)$, omission $(\mathrm{Z}=-2.02$, $p=.04)$ and addition $(Z=-3.37, p=.00)$, when applying the diagnostic software, compared to the classic evaluation method.

And according to the comparative study of the listening population, in comparison to print-oriented and computer-assisted multiple choice for learning English as a second language, conducted by García and Arias (2000), it has been proven that computers increase motivation and effective learning. The research shows that students find improvements in the grammar domain, adoption of vocabulary and pronunciation when they have computerassisted sources.

In regard to the research in this paper, which mainly outlines the better results in favor of the application program, the research of De Macedo, Capovilla, Diana, Orsati and Nikaedo (2004), which presented the research of the created test battery (BALS On-line) for evaluating the development of language skills of deaf students in Portuguese and Libras via the World Wide Web (WWW) Internet Service, by evaluation of three out of six computer test batteries on hearing children, comparing the obtained data in this way with the data obtained from the paper-and-pencil test, the study found out that they are compatible.

In the process of developing a software, the scientists and engineers study various are as and techniques of designing software with a view to efficiently and effectively sorting and retrieving information. Many factors must be put into consideration when writing a software (Dunmade et al. 2009).
Better responses to software solutions in the work with deaf persons are in favor of the researches by Segers and Verhoeven (2003), which have shown that using computer programs in treatment increases the vocabulary in a very short period of time, and that in working with young children, very little help is needed.

The aim of the research conducted by Hasanbegović and Mahmutović (2014) was to determine the development of syntax in language development of children who are deaf or hard-of-hearing, who are taught to new dynamic linguistic features with the help of computers. The sample consisted of 70 children who are deaf or hard-of-hearing, aged 7-17 years. To assess language development were applied following variables: total number of words used, the total number of different words used, the correct and incorrect statements (sentences) of the respondents. The results showed a significant improvement of the experimental group and that dynamic computer programming activities, which were challenged participants of the experimental group, contribute to a better linguistic competence of children who are deaf or hard-of-hearing.

Also, the purpose of the paper by Debevc and Peljhan (2004) was to determine the effectiveness of web-based video lectures on demand for the deaf in comparison to the traditional method of teaching using a sign language interpreter. The web-based lectures presented are specifically designed for the deaf in education and rehabilitation. By using the SUMI questionnaire, they determined the usability of the user interface for comprehension and gathering of knowledge. They found that the system was usable according to the standards.

Better results of the respondents in our work with classical estimates of errors in writing (smaller number of errors) can be caused by the earlier mastery and pencil training, compared to computer writing-typing, as well as ways of writing. When writing with a pencil, the student follows and writes the sequence of thoughts, while typing the letters on the computer, in addition, he must first find them on the keyboard because of what he can make mistakes.

In addition to the results that show a statistically significant difference between the variables mentioned, and for the variable partial naming of concepts and writing substitutions, there is a diagnostic but not statistically significant difference in the benefit of the diagnostic software. 


\begin{tabular}{|c|c|c|c|}
\hline Variables & $\mathbf{Z}$ & $p$ & $\mathbf{r}$ \\
\hline Understanding words & -3.26 & .00 & -.35 \\
\hline Naming of concepts & -2.05 & .04 & -.22 \\
\hline Partial naming of concepts & -.71 & .48 & -.08 \\
\hline Pronunciation omission & -1.63 & .10 & -.17 \\
\hline Pronunciation substitution & -.06 & .95 & -.07 \\
\hline Reading words with understanding & -3.65 & .00 & -.39 \\
\hline Reading words without understanding & -3.03 & .00 & -.32 \\
\hline Word writing & -2.71 & .01 & -.29 \\
\hline Total errors in writing & -4.89 & .00 & -.51 \\
\hline Writing omission & -2.02 & .04 & -.21 \\
\hline Writing substitution & -.56 & .58 & -.06 \\
\hline Writing addition & -3.37 & 00 & -.36 \\
\hline Writing metathesis & -1.09 & .28 & -.11 \\
\hline
\end{tabular}

T-test showed that differences, determined by descriptive analysis, are not statistically significant, but for all three variables there are diagnostically significant differences in the benefit of the diagnostic program (Table 3). This also confirmed the need for the preference of this method of evaluation. The most significant differences were observed in the pronunciation distortion. The results present on the variable word repeating in two ways of evaluating were expected because the evaluation of this variable was an excuse for verifying the pronunciation of the voices and determining any mistakes where the investigators investigated that the respondents repeated the word several times and were not given a great freedom of expression, as in evaluation of other variables.

Comparison of the results of the effectiveness of two methods of evaluation, based on the same diagnostic content, carried out at the same time, with the same sample of respondents, which showed the advantage of the IT diagnostic software compared to the classical evaluation, and since these results on most variables for the evaluation of speech-language development are statistically significant too, strongly suggests the need for IT improvement of the diagnostic process in the rehabilitation of hearing and speech.

Table 3 T- test results

\begin{tabular}{|c|c|c|c|}
\hline Variables & $\mathbf{t}$ & df & $p$ \\
\hline Word repeating & -1.57 & 44 & .12 \\
\hline Total errors in repeating the word & .93 & 44 & .36 \\
\hline Pronunciation distortion & 1.70 & 44 & .10 \\
\hline
\end{tabular}

Acorrding to Haug (2011) „Many paper-and-pencil tests have been converted to computer-based or webdelivered tests. Test content may not change, but two of the main ad-vantages are that scores are stored automatically and that subjects can receive a report of their performance immediately after completing the test. Choi, Kim, and Boo (2003) compared the same language test delivered in paper-and-pencil and computer-based versions and found that scores from both formats were comparable."

In the approach proposed by Zalewska et al. (1990), the deaf child is not seen as an object of the speech education and where the specialists concentrate on the child as a whole--with his various emotional needs and psychical traits. According to that way of seeing the deaf child, they organized the diagnosticrehabilitation courses for small deaf children and their parents ( 9 children aged 1.8-5 years). They found these courses as a method opening new perspectives in the process of the diagnosis and rehabilitation in the small deaf children.

While we still need to develop a better understanding of how deaf and hard of hearing children learn, we are cognizant of the fact that no single approach or strategy will provide the solution. We need to move away from standardized tests to assessments that will inform teachers, parents, and students through individually referenced performance measures. While there is little research to guide us, only when we have valid and reliable progress monitoring measures will we be able to identify instructional strategies and audiological, medical, and communication interventions that are effective or ineffective for a child (Rose, 2007). 


\section{CONCLUSION}

Based on the results of the research it can be concluded that there is a significant difference in the implementation of diagnostic procedures for the evaluation of the basic speech-language development indicators, when applying two different methods of evaluation, on all examined indicators for determining their effectiveness. This difference is also statistically significant when evaluating the understanding of words, naming of concepts, reading words with understanding and writing words, in favor of the application diagnostic software, in comparison to the classic evaluation method. Applied software-based diagnostics, both theoretically and in practical terms, provide a more efficient and effective way of implementing diagnostic procedures for evaluating speech-language development than classical (paper-pencil) estimation methods. Computer-adapted diagnostic procedures, as a technical-technological approach to diagnosis, simplify and facilitate both diagnostic and re/habilitation procedures to the audiologists.

\section{REFERENCES}

Debevc, M., \& Peljhan, Z. (2004). The role of video technology in on-linelectures for the deaf. Disability and Rehabilitation, 26(17), pp.1048-1059. doi: 10.1080/09638280410001702441

Dotter, F. (1996). Computer for the Deaf (and Hearing-Impaired): Towards an Integrated Solution from a Linguistic Standpoint. Retrived from: http://bidok.uibk.ac.at/ library/dotter-comp4deaf-e.html

Dunmade, A. O., Dunmade, A. D. Taiwo O. A., Tomori A. R. \& Komolafe T. M. (2009). A Software System for Diagnosis and Classification of Deafness. European Journal of Scientific Research, 25(4), 597-605. Retrived from: http://www.eurojournals.com/ejsr_38_2_05.pdf

Kostić, Đ., Vladisavljević, S., \& Popović, M. (1983): Speech and Language Testing. Belgrade: Institute for Textbooks and Teaching Resources

Gaad, N.E. \& Qaryouti, A. I. (2002). Effect Of Using Computers In Teaching First Grade Deaf Children In Un ited Arab Emirates. Journal of Faculty of Education UAEU, 17 (19), 53-63. Retrived from: http://www.fedu.uaeu.ac.ae/ journal/docs/pdf/pdf19/issue19-artical5.pdf

García, R.M. \& Arias, V.F. (2000), A Comparative Study in Motivation and Learning through Print-Oriented and Computer-Oriented Tests. Computer Assisted Language Learning 13(4-5):457-465 · DOI: 10.1076/09588221(200012)13:4-5;
Hasanbegović, H. (2006). Rehabilitation programs in the language development of deaf, doctoral dissertation. Tuzla: University in Tuzla

Hasanbegovic, H. \& Mahmutovic, E. (2014). Syntax Development in Language Education of Children Who Are Deaf or Hard-of-Hearing by Usage of Modern Technology. Sino-US English Teaching, 11 (5), 307-315

Mahmutović, E. \& Hasanbegović, H. (2017). Application of Software in the Diagnosis of Hearing Impairment. HUMAN, International Journal for interdisciplinary studies Human Research in rehabilitation, 7(2), 78-84

Haug, T. (2011). Adaptation and evaluation of a German Sign Language Test - A computer-based receptive skills test for deaf children ages 4-8 years old. Hamburg, Germany: Hamburg University Press. Retrived from: http://hup. sub.uni-hamburg.de/purl/HamburgUP Haug

Larson, W. J. (2000) Testing Oral Language Skills via the Computer, CALICO Journal 18(1), 53-66. doi: http://dx.doi. org/10.11139/cj.18.1.53-66

Macedo, C. E., Capovilla, C. F., Diana, C. Orsati, F. \& Nikaedo, C. (2004). Development of a Test Battery to Assess Deaf Language Skills via WWW. Retrived from: http://www. ip.usp.br/lance/artigos/macedo_capovilla_diana_orsati_ nikaedo_2004.pdf

Marschark, M. (2001). Looking beyond the obvious: Assessing and Understanding Deaf Learners. Retrived from: http://www.acfos.org/publication/ourarticles/pdf/acfos3/ intro_marschark.pdf

Miller, M. (2006). Individual Assessment and Educational Planning: Deaf and Hard of Hearing Students Viewed Through Meaningful Contexts. U knjizi Moores, F. D. i Martin S. D. (Editors). Deaf Learners. Developments in Curriculum and Instruction (pp. 161-177). Washington, D.C. 20002: Gallaudet University Press

Rose, S. (2007). Monitoring Progress of Students Who Are Deaf or Hard of Hearing. Retrived from: http://www.studentprogress.org/library/ArticlesResearch/SPMforstudentwhoaredeaforhardofhearing.pdf

Segers, E. i Verhoeven, L. (2003). Effects of vocabulary training by computer in kindergarten. Journal of Computer Assisted Learning, 19(4), 557-566. doi: 10.1046/j.02664909.2003.00058.x

Shemesh, R. (2013). Hearing Impairment: Definitions, Assessment and Management. U: Stone, H. J. i Blouin, M. (Editors). International Encyclopedia of Rehabilitation. Retrived from: http://cirrie.buffalo.edu/encyclopedia/en/ article/272

Vuletić, D. (1990). Articulation Test. Faculty of Defectology of the University of Zagreb

Zalewska, M., Wojciechowska, E., Schier, K., SobieszczańskaRadoszewska, L., Siedlecka, H. i Bralczyk T. (1990). Searching new diagnostic and rehabilitation techniques in small deaf children (abstract). Retrived from: http:// www.ncbi.nlm.nih.gov/pubmed/2152417 